\title{
"SATELLITE-DRIVEN MODELING APPROACH FOR MONITORING LAVA FLOW HAZARDS DURING THE 2017 ETNA ERUPTION,
}

\author{
Annalisa Cappello*,1, Gaetana Ganci ${ }^{1}$, Giuseppe Bilotta ${ }^{1}$, Alexis Hérault ${ }^{1,2}$, Vito Zago ${ }^{1,3}$, \\ Ciro Del Negro ${ }^{1}$ \\ (1) Istituto Nazionale di Geofisica e Vulcanologia, Sezione di Catania, Osservatorio Etneo, Catania, Italy \\ (2) Conservatoire National des Arts et Métiers, Paris, France \\ (3) Dipartimento di Ingegneria Elettrica Elettronica e Informatica, Università di Catania, Catania, Italy
}

Article history

Receveid June 1, 2018; accepted August 31, 2018.

Subject classification:

HOTSAT; MAGFLOW; Satellite remote sensing; Lava flow mapping; Hazard monitoring.

\begin{abstract}
The integration of satellite data and numerical modeling represents an efficient strategy to find immediate answers to the main issues raised at the onset of a new effusive eruption. Satellite thermal remote sensing can provide a variety of products suited to timing, locating, and tracking the radiant character of lava flows, including the opening times of eruptive vents. The time-series analysis of thermal satellite data can also provide estimates of the time-averaged discharge rate and volume. High-spatial resolution multispectral satellite data complement field observations for monitoring the lava emplacement in terms of flow length and area. All these satellite-derived parameters can be passed as input to physics-based numerical models in order to produce more accurate and reliable forecasts of effusive scenarios during ongoing eruptions. Here, we demonstrate the potential of the integrated application of satellite remote sensing techniques and lava flow models during the 2017 eruptive activity of Mt Etna. Remote sensing data from SEVIRI are analyzed by the HOTSAT system to output hotspot location, lava thermal flux, and effusion rate estimation. This output is used to drive, as well as to continuously update, lava flow simulations performed by the physics-based MAGFLOW model. We also show how Landsat-8 and Sentinel-2 satellite data complement the field observations to track the flow front position in time and add valuable data on lava flow advancement with which to iteratively validate the numerical simulations.
\end{abstract}

\section{INTRODUCTION}

During the first half of 2017, Mount Etna (Sicily, Italy) showed an intense eruptive activity in the summit area (Figure 1). The first eruptive episode started from a vent (V1 in Figure 1) located in the old "saddle" between the South-East Crater (SEC) and the New Southeast Crater (NSEC) on the late afternoon of the 27 February 2017 [INGV Weekly Report $N^{\circ} 10 / 2017$ ]. It was characterized by the emission of lava fountains, pyroclastic material, and a lava overflow towards the Valle del Bove (VdB). This episode, similar to dozens of erup- tive events from the summit craters of Etna over the past decades [Cappello et al., 2013; 2019], was the $57^{\text {th }}$ from the formation of the NSEC in 2011 on the low eastern flank of the SEC. From 28 February to 1 March, the eruptive activity continued with minor fluctuations, drastically decreasing in intensity on 2 March. The lava flow reached Monte Frumento Supino (MFS), which diverted it to the southwest and southeast (with a shorter branch). During this event a new pyroclastic cone formed around the active vent, rapidly reaching the height of the SEC and NSEC cones at $~ 3330 \mathrm{~m}$ a.s.l. [Ganci et al., 2018]. 


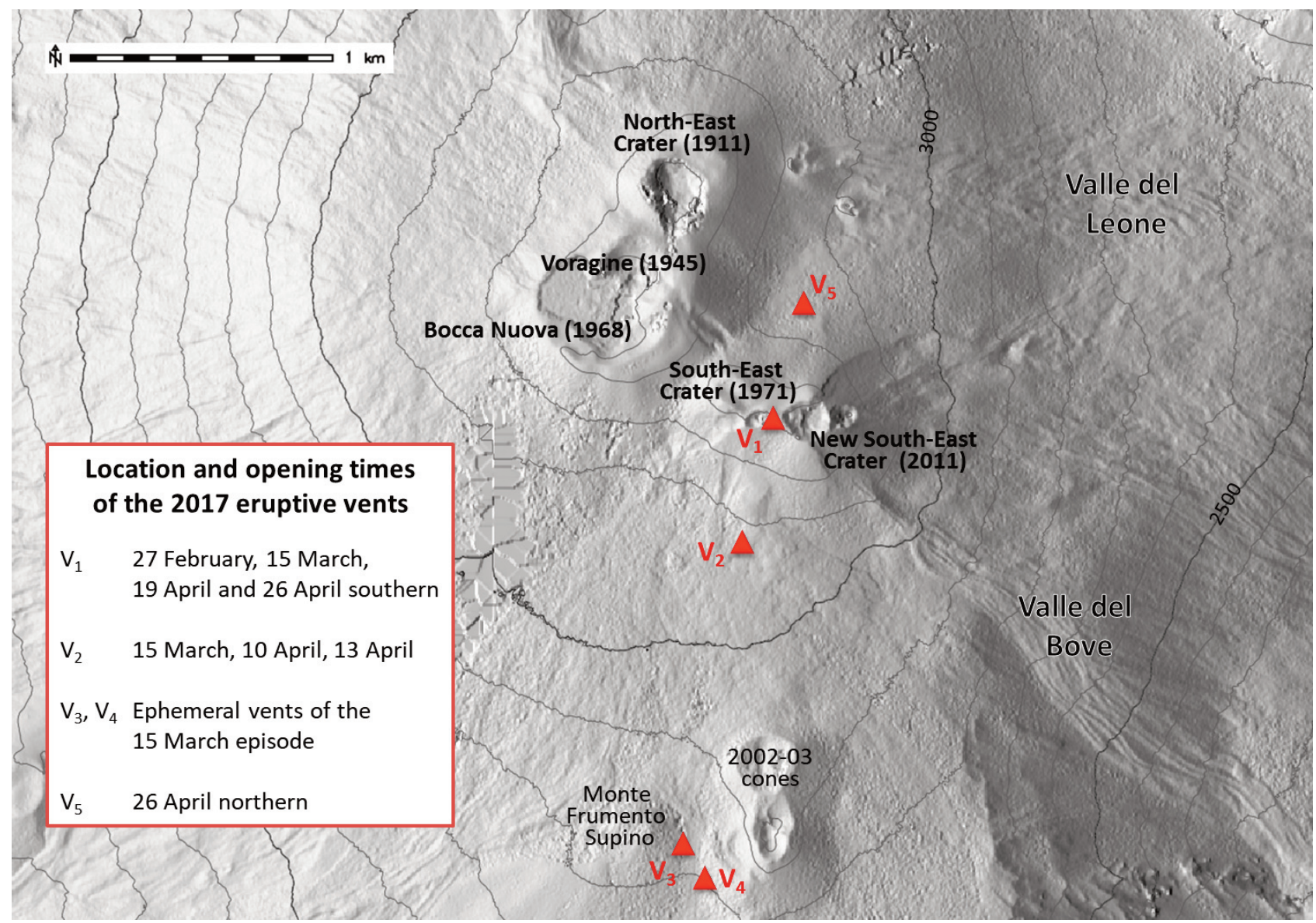

FIGURE 1. Location and opening times of the 2017 eruptive vents: $V_{1}$, which is located in the old "saddle" between the South-East Crater and New South-East Crater, opened on 27 February and reactivated on 15 March, 19 April and 26 April; $V_{2}, V_{3}$ and $V_{4}$ opened during the long-lasting effusive event started on 15 March; V5 opened on 26 April. North-East Crater, Voragine, Bocca Nuova, South-East Crater and New South-East Crater are the five craters active on the summit of Mt Etna. The formation year of each crater is enclosed in brackets. Contour interval $=100$ meters.

After a two week break, the second eruptive episode of 2017 started on the morning of 15 March, from the same vent opened on 27 February $\left(\mathrm{V}_{1}\right.$ in Figure 1) and continued from a pit crater opened on the south flank of the new pyroclastic cone $\left(\mathrm{V}_{2}\right.$ in Figure 1$)$. The lava flow expanded both to the southeast and southwest, diverted by the eruptive cones formed during the 20022003 flank eruption, and partially covered the lava flow field emplaced during the February 2017 event. At the beginning of April the lava flow show different stages of development and emerged from two ephemeral vents opened downstream $\left(V_{3}\right.$ and $V_{4}$ in Figure 1). This eruptive episode ended on the night between 8 and 9 April.

This long effusive activity was followed by four short-term eruptive events occurred on 10,13, 19, and 26 April. On April 10 $0^{\text {th }}$, the eruptive vent at the southern base of the NSEC was reactivated $\left(V_{2}\right.$ in Figure 1$)$, from which a small lava flow was emitted to the south for about 24 hours [INGV Weekly Report N¹6/2017]. On the evening of 13 April the eruptive activity restarted from vent $V_{2}$, with the lava that flew downhill on the western wall of the $\mathrm{VdB}$, overlapping the lava flow of 10-11 April, and stopping late evening on 14 April. In the morning of 19 April $\mathrm{V}_{1}$ reactivated with a new lava flow that followed the same path of the two previous effusions (10-11 and 13-15 April), towards the western edge of $\mathrm{VdB}$. Also this eruptive episode ended the next day.

The last effusive episode of 2017 started on the night between 26 and 27 April. Two different eruptive vents opened on the east-southern $\left(\mathrm{V}_{1}\right.$ in Figure 1$)$ and east-northern $\left(\mathrm{V}_{5}\right)$ flank of the SEC, which fed two lava flows, one directed again towards $\mathrm{VdB}$ and the other to Valle del Leone (VdL). The eruptive activity continued during the morning of 27 April and began to decrease around midday; the lava flows were still fed until the afternoon of the same day [INGV Weekly Report 
$\left.N^{\circ} 18 / 2017\right]$. Since then the activity of Etna has undergone considerable change, as eruptive episodes with lava emission have no more occurred at the SECNSEC area throughout 2017.

Here we demonstrate how the integration of satellite data and physical models has enabled to monitor lava flow hazards during the eruptive activity of $\mathrm{Mt}$ Etna in the first four months of 2017. By monitoring, we mean here both following the manifestations of the eruption once it has started, as well as forecasting the areas potentially threatened by lava in an effusive scenario. To deal effectively with this crisis, we used the HOTSAT system [Ganci et al., 2016] to analyze high temporal resolution geostationary MSG SEVIRI data, with the aim of detecting thermal anomalies due to active lava flows and calculating the time-averaged discharge rate (TADR). The SEVIRI-derived TADRs were then used as input of the MAGFLOW model [Cappello et al., 2016b] to produce different scenarios as eruptive conditions change. The detailed reconstruction of the chronology of vent opening, as well as lava flow field growth, was performed by using high spatial-resolution satellite data from the polar-orbiting Landsat- 8 and Sentinel-2A sensors. The satellite-derived lengths and areas of the actual flow field were also used to perform an iterative validation of the MAGFLOW lava flow simulations. The objective of such efforts is to improve confidence in the interpretation of final model simulations and to document how the model results could be incorporated into decision support systems.

\section{THE 2017 ERUPTIVE EVENTS FROM SATEL- LITE}

\subsection{TADR AND VOLUME ESTIMATION FROM SEVIRI}

Satellite remote sensing and data processing techniques have proved well suited to complement field observations to allow timely event detection for effusive events, as well as extraction of parameters allowing lava flow tracking. During the 2017 Etna eruptions we used the HOTSAT volcano hotspot detection system [Ganci et al., 2012b; 2016] to analyze mid and thermal infrared channels acquired by SEVIRI to output hotspot location, lava thermal flux, and effusion rate estimation. When a thermal anomaly is detected, HOTSAT estimates a heat flux curve from the thermal flux radiated by lava for each SEVIRI image, which is then converted in time-averaged discharge rate (TADR) adopting a direct relationship between the radiant heat loss from an active lava flow and the effusion rate [e.g., Harris et al., 1997; Wright et al., 2001]. Recent laboratory experiments [Garel et al., 2015] have supported the roughly linear relationship between radiated power and effusion rate when the thermal steady state of the flow is reached, and this can also occur in the presence of temporal variations of the supply rate if the hottest flow regions are considered. Since this relationship depends on different lava parameters (e.g. rock density, heat capacity, vesicularity, emissivity, etc.), HOTSAT outputs a minimum and maximum TADR by considering the parameter value ranges, resulting in a volume variation of $\pm 25 \%$ [Ganci et al., 2016].

The relationship between radiant heat flux and effusion rate cannot be used for short-lived eruptive episodes, since a thermal steady state is not reached [Garel et al., 2012]. Moreover, the thermal activity of the peak fountaining phase can be masked by the presence of tephra or ash [Vicari et al., 2011]. For these reasons, during short lava fountaining events, we estimate the erupted volume and mean output rate (MOR) by modelling the plume- and saturation-free cooling curve, apparent in high temporal resolution thermal data acquired by geostationary sensors [Ganci et al., 2012a]. Indeed, the SEVIRI-derived heat flux curves of short-lived eruptive events show a typical waveform characterized by a slow increasing heat flux (phase 1), main fountaining activity (phase 2) and cooling (phase 3). In this case, volumes can be inferred by minimizing the difference between the modeled and the SEVIRI-derived cooling curve, while the TADR can be assumed constant and equal to the MOR [Latutrie et al., 2016].

For the eruptive events occurred at Etna in 2017, we considered both the duration and the possibility to isolate the cooling phase in the waveform of the SEVIRI-derived radiative heat flux. Following this selective principle, we applied the standard HOTSAT to catalogue the first two eruptive episodes in February and March, and the method that uses cooling curves to characterize the four short-term events of April.

The TADR and volume estimations derived from SEVIRI data are plotted in Figure 2. Results obtained for each event (i.e. GMT date and hour of the first thermal anomaly detected by HOTSAT, duration, maximum value of the radiative power, mean output rate and lava volume) are summarized in Table 1. The peak of 11.58 


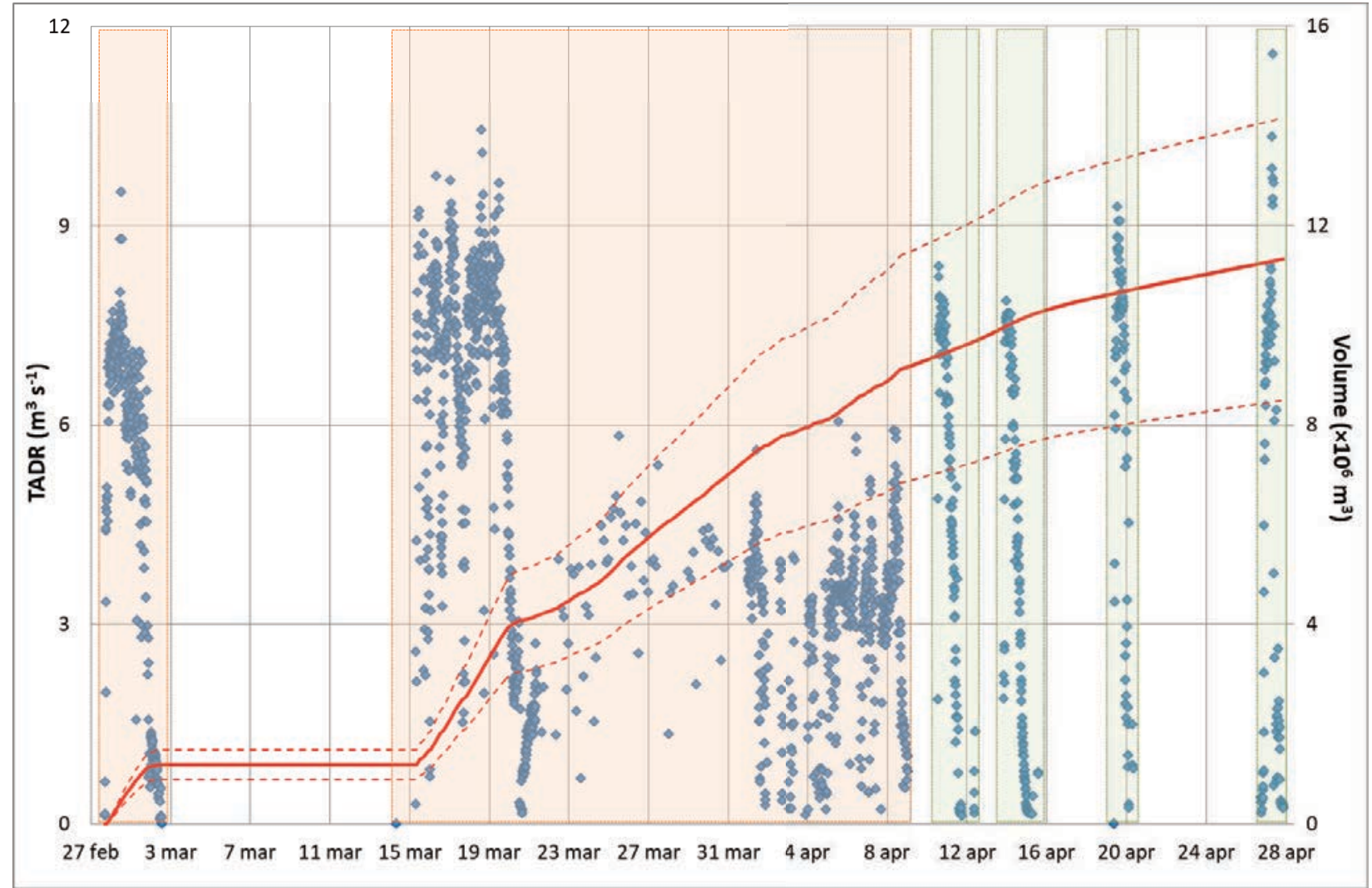

FIGURE 2. TADR values (blue diamonds) and cumulative lava volumes (red line) with the minimum and maximum estimates (red dotted lines) computed from SEVIRI data. The red bars mark the two long-lasting effusive periods of 2017 (February and March), while the green areas highlight the four shorter events of April.

$\mathrm{m}^{3} / \mathrm{s}$ in TADR is recorded during the last eruption, on 27 April at 7:56 GMT (Figure 2). Estimates of lava volumes vary between $0.47 \times 10^{6} \mathrm{~m}^{3}$, erupted on 19 April, and $7.96 \times 10^{6} \mathrm{~m}^{3}$, erupted during the longest eruptive period that goes from 15 March to 9 April (Table 1), reaching a total volume of $\sim 11.3 \pm 2.8$ million of $\mathrm{cu}-$ bic meters over the entire period. Durations range from 14.5 hours occurred on 19 April to 24.7 days for the long-lasting eruption started on 15 March. MOR, which was estimated as the ratio between volume and duration, shows an increasing trend, varying between 3.73 (on $15 \mathrm{March}$ ) and $10.38 \mathrm{~m} 3 / \mathrm{s}$ (on 26 April).

\begin{tabular}{|c|c|c|c|c|c|}
\hline Event number & First Hotspot & Duration (minutes) & Max Radiative Power (W) & $\operatorname{MOR}\left(\mathrm{m}^{3} \mathrm{~s}^{-1}\right)$ & Lava Volume $\left(\mathrm{m}^{3}\right)$ \\
\hline 1 & 27 Feb 16.56 & 4156 & $8.81 \mathrm{E}+09$ & 4.77 & $1.19 \mathrm{E}+06$ \\
\hline 2 & 15 Mar 07:42 & 35580 & $9.67 \mathrm{E}+09$ & 3.73 & $7.96 \mathrm{E}+06$ \\
\hline 3 & 10 Apr 13:26 & 1080 & 7.77E+09 & 8.12 & $0.53 E+06$ \\
\hline 4 & 13 Apr 20:42 & 1020 & $7.28 \mathrm{E}+09$ & 9.30 & $0.57 \mathrm{E}+06$ \\
\hline 5 & 19 Apr 09:30 & 870 & $8.59 \mathrm{E}+09$ & 8.96 & $0.47 \mathrm{E}+06$ \\
\hline 6 & 26 Apr 18:11 & 975 & $1.07 \mathrm{E}+10$ & 10.38 & $0.61 E+06$ \\
\hline
\end{tabular}

TABLE 1. Event number, GMT date and hour of the first hotspot, duration, maximum value of the radiative power, Mean Output Rate (MOR) and lava volume of the 2017 eruptive events at Mt Etna as retrieved from SEVIRI data. 


\subsection{LAVA FLOW MAPPING USING MULTISPECTRAL IMAGES}

High-spatial-resolution satellite data provides a synoptic view of a volcano across multiple wavelengths, filling the observational gaps in the spatiotemporal evolution of lava flows, particularly for remote effusive eruptions [Del Negro et al., 2016]. In particular, satellite images acquired by Landsat- 8 and Sentinel-2A offer $10 \mathrm{~m}$ to 100 m multi-spectral global coverage. The Landsat-8 satellite (launched in 2013) carries a two-sensor payload, OLI and TIRS, and collects 11 spectral bands varying from 15 meter to 100 meter resolution. The equatorial repeat cycle is 16 days. The MSI sensor carried by Sentinel-2 acquires 13 spectral bands that are highly complementary to data acquired by the Landsat-8 OLI, with a spatial resolution of 10 to 60 meters. The revisit time at the equator is 10 days.

In order to compile a detailed chronology of the lava flow emplacements during the 2017 Etna eruptions, we combined field observations with Landsat-8 and Sentinel-2A data. In particular, we used the Sentinel-2A images acquired on 16, 19 and 26 March and the Landsat-8 image on 27 March to follow the eruptive dynamics of the longest eruptive episode (Figure 3), while Landsat-8 images on 2 March, 12, 19, and 28 April, and Sentinel-2A images on 8 and 15 April were exploited to map the final lava flow fields (Figure 4). These multispectral images were used to track the flow front position through time, to locate the eruptive vents and to outline the emplaced lava flow areas.

The satellite-derived morphological data of lava flow surfaces were calculated by adaptive local thresholding in GRASS GIS and used as reference values to accuracy and effectiveness of lava flow simulations.

\section{SCENARIO FORECASTING USING THE MAGFLOW MODEL}

When an effusive eruption is in progress, the hazard posed by lava flows to threatened communities can be assessed by modeling the probability of lava flow in-
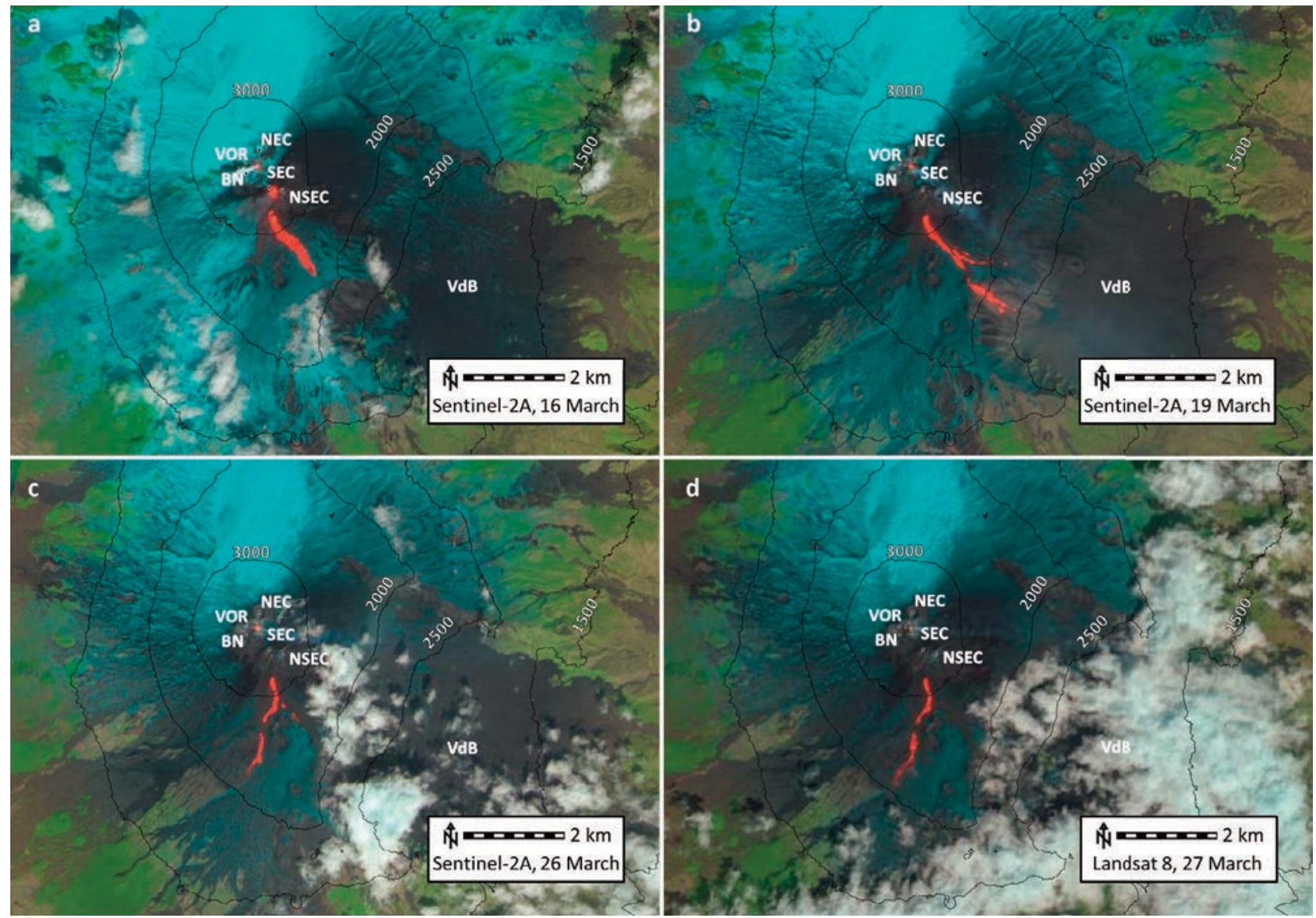

FIGURE 3. Advance of the lava flow during the longest eruptive event started at Etna on 15 March 2017 and ended after about 25 days. These are color composite images using bands SWIR-1/NIR/Red of Landsat-8 (bands 6/5/4) and Sentinel-2A (bands 11/8A/4). Active lava flow stands out as bright red pixels due to the strong signal in the SWIR channel. NEC $=$ NorthEast Crater, VOR $=$ Voragine, BN $=$ Bocca Nuova, $\mathrm{SEC}=$ South-East Crater, NSEC $=$ New South-East Crater, VdB $=$ Valle del Bove. 

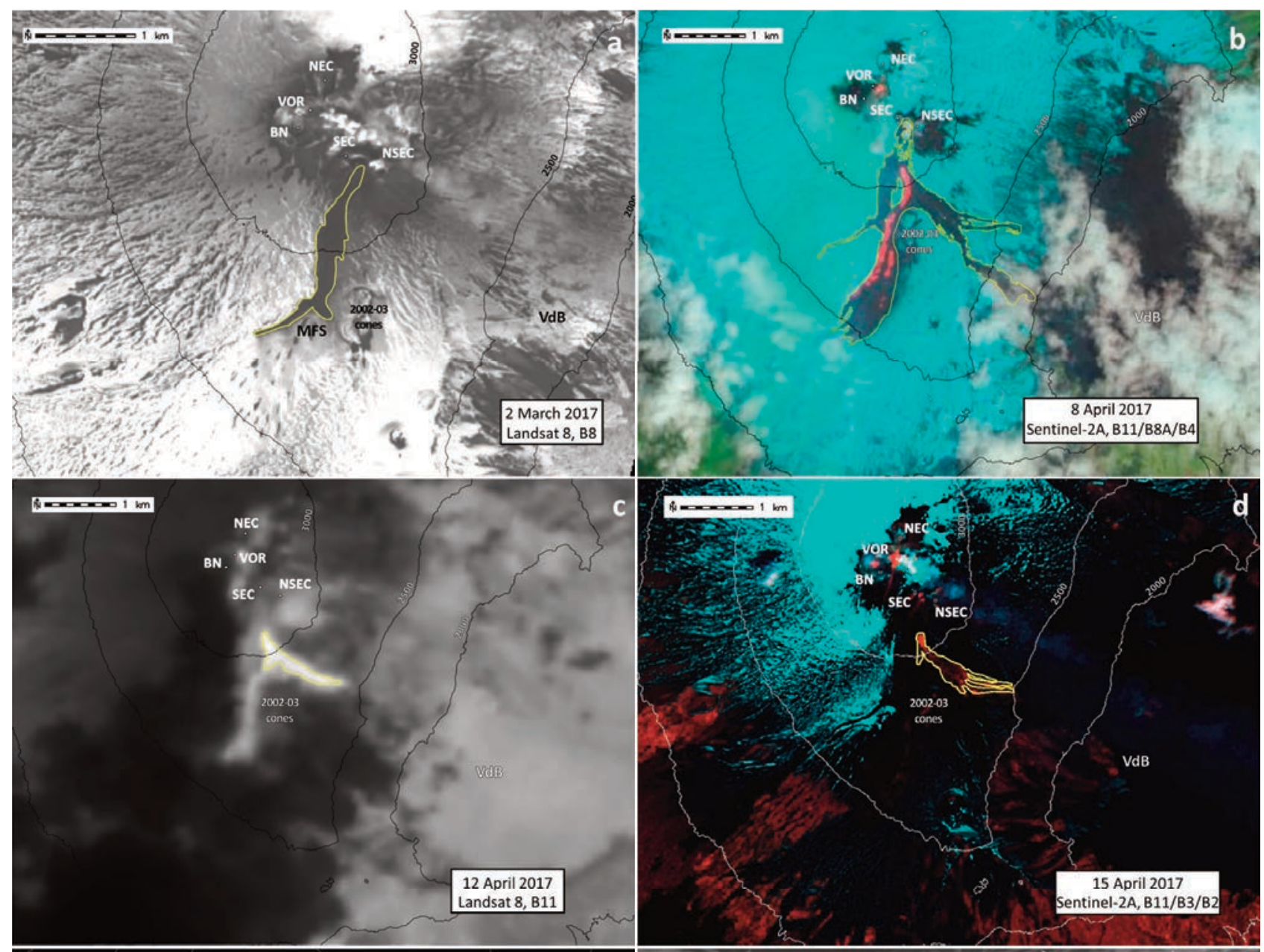
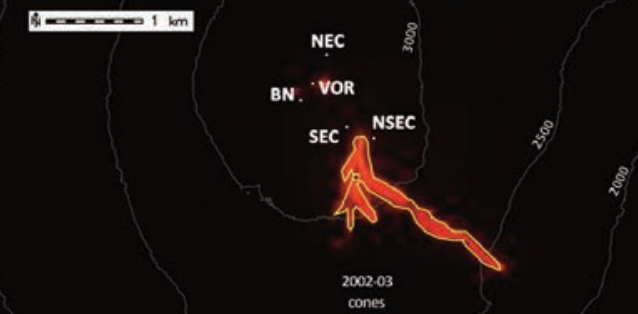

$\mathrm{VdB}$

19 April 2017 Landsat $8, \mathrm{~B} 6 / \mathrm{BS} / \mathrm{B} 4$
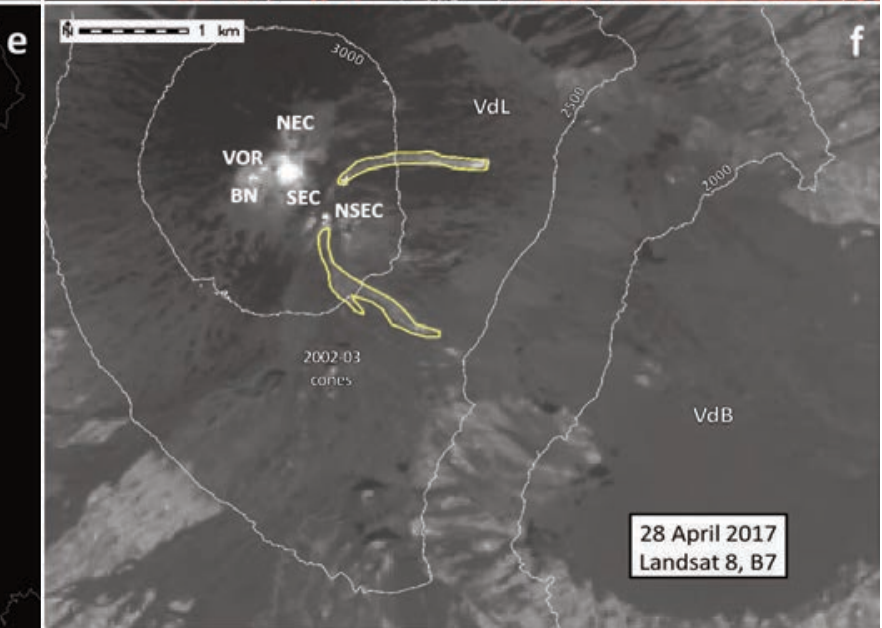

FIGURE 4. Final lava flow fields as shown by Landsat-8 and Sentinel-2A images. For Landsat-8, spatial resolution is 15 meters for band 8 (panchromatic), 30 meters for bands 4 (Red), 5 (NIR), 6 (SWIR-1) and 7 (SWIR-2), and 100 meters for band 11 (TIR-2). Spatial resolution of Sentinel-2A bands is 20 meters. NEC $=$ North-East Crater, VOR $=$ Voragine, BN $=B$ Bocca Nuova, SEC $=$ South-East Crater, NSEC $=$ New South-East Crater, MFS $=$ Monte Frumento Supino, VdB $=$ Valle del Bove, $\mathrm{VdL}=$ Valle del Leone.

undation into affected areas [Vicari et al., 2011; Cashman et al., 2013; Del Negro et al., 2016]. In addition to topography, the behavior of lava flows is controlled by a number of parameters such as effusion rate, rheology, heat loss, viscosity, velocity, and flow morphology all of which are interconnected [Walker, 1973; Harris and
Rowland, 2001]. Each of these parameters does not impact the lava emplacement in the same way; the magnitude of their effect varies with the distance from the vent and also with the timescale of observations [Calvari and Pinkerton, 1998]. This means that it is necessary to relate changing eruption conditions to the re- 


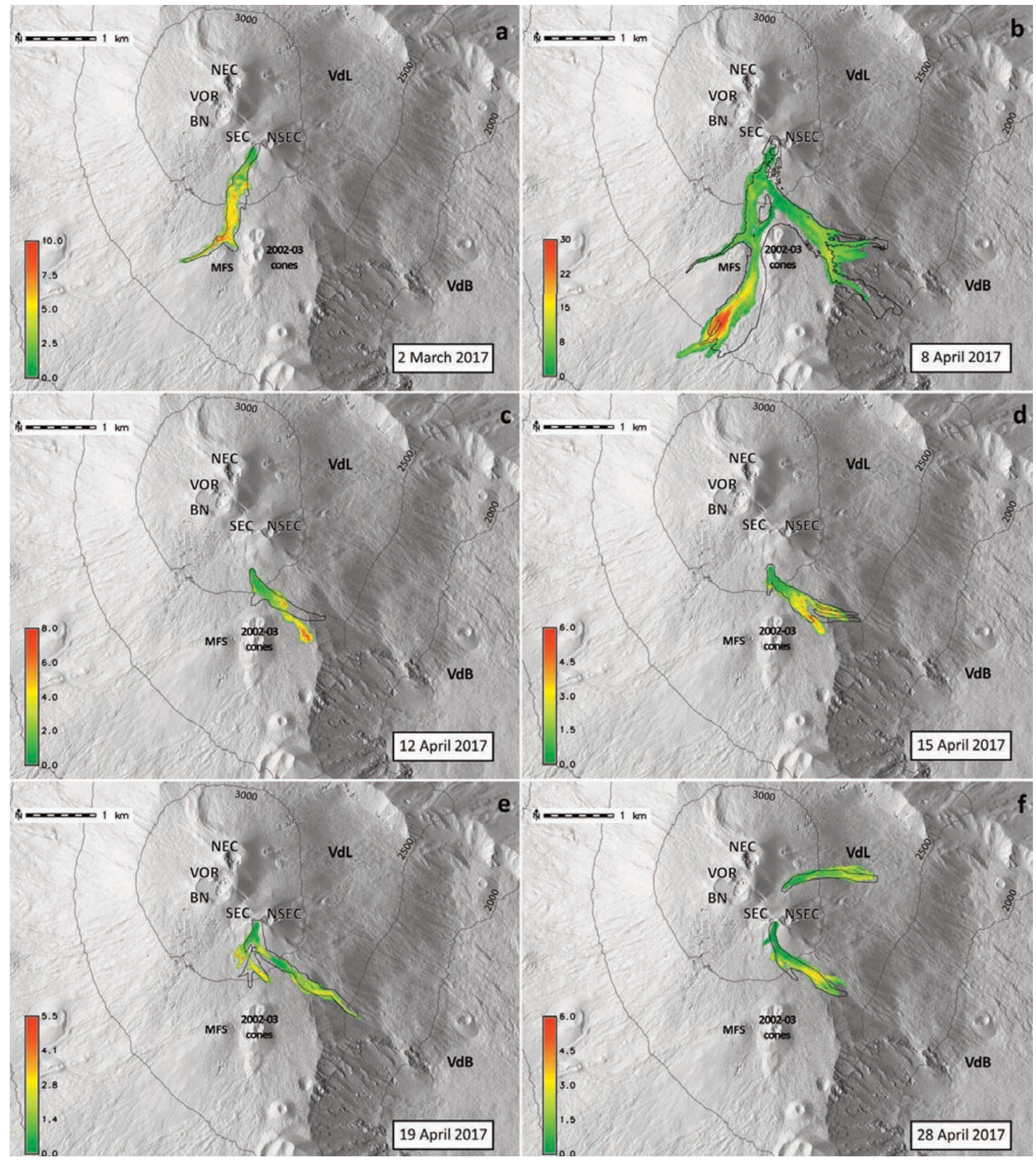

FIGURE 5. Simulated lava flow fields of the 2017 Etna eruptions. The colors indicate flow thickness in meters. The outlines of actual flow fields (black curves) are based on Landsat-8 and Sentinel-2A images. NEC $=$ North-East Crater, VOR $=$ Voragine, $\mathrm{BN}=$ Bocca Nuova, SEC $=$ South-East Crater, NSEC $=$ New South-East Crater, MFS = Monte Frumento Supino, $\mathrm{VdB}=$ Valle del Bove, $\mathrm{VdL}=$ Valle del Leone.

sulting flow extent. As such, lava flow models using a sound physical description of the emplacement process and rheology of lava, including the way in which effusion rate changes during an eruption and how this affects lava spreading, are of paramount importance, as effusion rates can be highly variable over time [Lautze et al., 2004; Hérault et al., 2009; Bilotta et al., 2012]. On the other hand, timely forecasts of the areas that a lava flow might invade require as frequent and accurate data as possible on the eruptive activity.

Unfortunately, the location, intensity, extent, and advancing of flows are difficult to observe with common 
field methods because of the large size and poor accessibility of the inundated areas [Calvari et al., 2003]. Satellite observations offer great promise to collect this information and allow the manifestations of the eruption to be followed once it has started [Ganci et al., 2012b]. Satellite thermal remote sensing of hotspots related to effusive activity can effectively provide a variety of products suited to timing, locating, and tracking the radiant character of lava flows [Cappello et al., 2016a]. Hotspots show the location and occurrence of eruptive events (vents). Discharge rate estimates may indicate the current intensity (effusion rate) and potential magnitude (volume). High-spatial resolution multispectral satellite data can complement field observations for monitoring the front position (length) and extension of flows (area). In parallel with this, lava flow simulation models have developed immensely since the introduction of the first cellular automata in the mid-1980's. Such physics-based models driven, or validated, by satellite-derived parameters are now capable of fast and accurate forecast of lava flow inundation scenarios (hazard).

To simulate the spatial and temporal evolution of lava flow fields, we developed the physics-based MAGFLOW model [Del Negro et al., 2008], which has been extensively used to forecast lava flow inundation scenarios both at Etna [Cappello et al., 2011a; 2011b; Vicari et al., 2011; Ganci et al., 2012b; Del Negro et al., 2013] and in other volcanoes worldwide [Kerestzuri et al., 2014; Cappello et al., 2015a; 2015b; Pedrazzi et al., 2015; Cappello et al., 2016a]. MAGFLOW is operational but needs reliable input of lava composition, precise location of eruptive vents, real-time effusion rate estimates, and accurate pre-eruption digital topography if it is to be effective.

In order to forecast the areas likely to be inundated by lava flows during the 2017 eruptions, we used the typical properties of Etnean basaltic rocks: density $(2600$ $\left.\mathrm{kg} / \mathrm{m}^{3}\right)$; specific heat capacity $\left(1150 \mathrm{~J} \mathrm{~kg}^{-1} \mathrm{~K}^{-1}\right)$; emissivity (0.9); solidification temperature (1173 K); extrusion temperature (1360 K). As pre-eruptive topographic base, we used a 5-m DEM of Etna that covers the summit craters and a portion of the south-east flank of the volcano, obtained by processing a tri-stereo Pléiades 1A imagery acquired on 18 July 2016 (downloadable from https://doi.pangaea.de/10.1594/PANGAEA.899176). The 3D processing of Pléiades images was performed using the free and open source MicMac photogrammetric library (http://micmac.ensg.eu), and took advantage of ground control points placed on Mt Etna. The locations and opening times of the eruptive vents through the different phases of activity (Figure 1) were determined by field measurements and satellite remote sensing. For the first two eruptions we used the SEVIRI-derived estimates of TADR computed by HOTSAT, while for the short eruptive episodes of April, we assumed that the MOR was constant during the event.

The comparison between the satellite-derived and simulated lava flow fields is reported in Figure 5. In general, a good agreement is achieved for all eruptive events, with the best results obtained during the first (Figure 5a) and last (Figure 5f) episodes. Even if a tight fit remains for the other eruptions, some differences can be noticed, mainly due to the topographic changes caused by the preceding events. Indeed, the SW branch of the eruptive episode started on 15 March partially covers the lava flow field emplaced in February 2017 (Figure 5b), while lava flows of 10, 13 and 19 April all follow the same path (Figures 5c-e).

\section{DISCUSSION}

In order to evaluate our ability to reproduce the lava flows emplaced during the 2017 Etna eruptions, we compared the areal dimensions of simulated and actual lava flow fields per each event (Table 2). The smallest actual area, extracted from Landsat- 8 data, is the one fed on the northern flank of the SEC towards VdL (0.143 $\mathrm{km}^{2}$ ). The biggest area, derived from Sentinel-2A imagery, is the one emitted during the longest eruptive event of 15 March (1.782 $\mathrm{km}^{2}$ ), representing 76\% of the total lava flow area $\left(2.331 \mathrm{~km}^{2}\right)$.

The goodness of fit between the actual and MAGFLOW-simulated areas was quantified using the three scores $\varphi, \mathrm{e}_{1}$ and $\varepsilon$ (Bilotta et al., 2012; Kereszturi et al., 2014; Cappello et al., 2016a; Del Negro et al., 2016): $\varphi$ is the intersection over union areas of the simulated and actual lava flows; $\mathrm{e}_{1}$ is the square root of $\varphi ; \varepsilon$ measures the percentage of actual lava flow area covered by the simulated one. The lower and upper bounds for all scores are zero (total mismatch) and one (complete overlap). The choice to provide values for all three fitness indices (Table 2) is motivated by the different behavior of $\varphi, \mathrm{e}_{1}$ and $\varepsilon$, and therefore the preference of one over the others, which is largely dependent on the shape of the emplacement [Bilotta et al., 2012].

Except for two cases ( $\varphi$ on 8 and 12 April), the ac- 


\begin{tabular}{|c|c|c|c|c|c|c|c|}
\hline Date & & Data source & Satellite-derived area $\left(\mathrm{km}^{2}\right)$ & Simulated area $\left(\mathrm{km}^{2}\right)$ & $\varphi$ & $\mathrm{e}_{1}$ & $\varepsilon$ \\
\hline 2 March & & Landsat-8 & $0.321 \pm 0.075$ & 0.362 & 0.645 & 0.803 & 0.790 \\
\hline 8 April & & Sentinel-2A & $1.782 \pm 0.473$ & 1.418 & 0.491 & 0.701 & 0.592 \\
\hline 12 April & & Landsat-8 & $0.197 \pm 0.095$ & 0.207 & 0.378 & 0.615 & 0.563 \\
\hline 15 April & & Sentinel-2A & $0.283 \pm 0.064$ & 0.299 & 0.576 & 0.759 & 0.752 \\
\hline 19 April & & Landsat-8 & $0.371 \pm 0.103$ & 0.326 & 0.501 & 0.708 & 0.627 \\
\hline \multirow[b]{2}{*}{28 April } & $\mathrm{N}$ & \multirow[b]{2}{*}{ Landsat-8 } & $0.143 \pm 0.045$ & 0.193 & 0.560 & 0.748 & 0.843 \\
\hline & $S$ & & $0.181 \pm 0.057$ & 0.261 & 0.512 & 0.716 & 0.827 \\
\hline Total & & & $2.331 \pm 0.912$ & 2.041 & 0.548 & 0.740 & 0.664 \\
\hline
\end{tabular}

TABLE 2. Comparison between actual and simulated lava flow areas of the 2017 Etna eruptions. For each event, the source image (Landsat-8 or Sentinel-2A) from which we extracted the actual area is indicated. Measurement errors were calculated by multiplying the satellite-derived perimeters by the pixel resolution. The three fitness scores, $\varphi, \mathrm{e}_{1}$ and $\varepsilon$, used to quantify the goodness of fit between the satellite-derived and simulated lava flow areas, range between 0 (worst case) and 1 (best case).

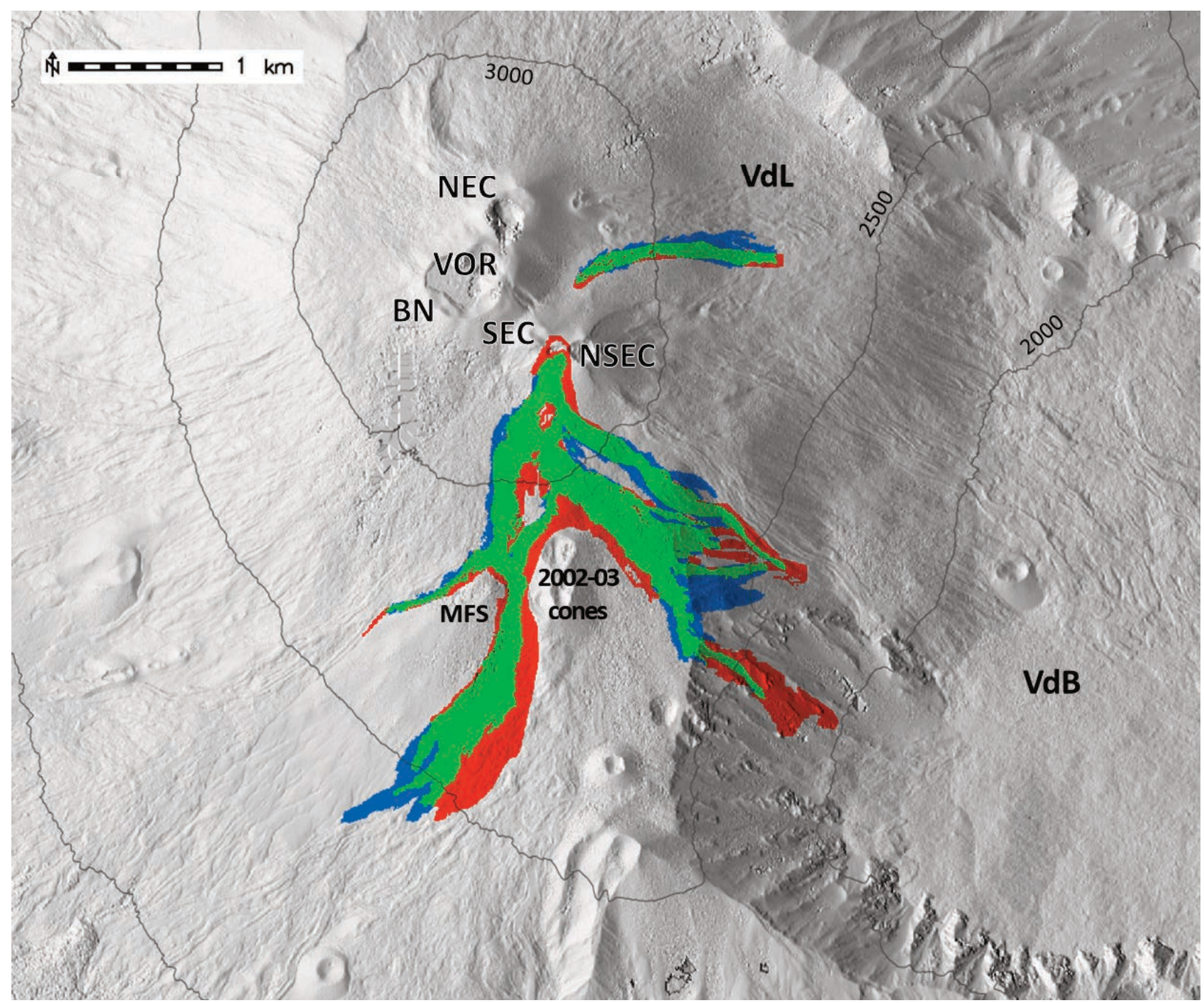

FIGURE 6. Visual comparison between the total actual and simulated lava flow areas of the 2017 Etna eruptions: the intersection area (true positive) is in green; the underestimated area (false negative) is in red; the overestimated areas (false positive) is in blue. NEC = North-East Crater, VOR = Voragine, BN = Bocca Nuova, SEC $=$ South-East Crater, NSEC $=$ New SouthEast Crater, MFS = Monte Frumento Supino, VdB = Valle del Bove, VdL = Valle del Leone. 
tual lava flow field is consistently well reproduced by the MAGFLOW model, with the three fitting scores higher than 0.5 for all eruptions (Table 2). The minimum values are obtained for the 12 April event, with $\varphi=$ 0.378 , e $1=0.615$ and $\varepsilon=0.563$. The maximum values are reached on 2 March $\left(\varphi=0.645, \mathrm{e}_{1}=0.803\right)$ and 28 April $(\varepsilon=0.843$ for the north branch, $\varepsilon=0.827$ for the south branch). The good agreement between the actual and simulated lava flows during these events is undoubtedly due to the fact that the lava flows emplaced in areas where no topographic features have been introduced by previous eruptions. This result confirms the importance of the availability of updated topography to improve the accuracy and reliability of simulated scenarios.

To facilitate the comparison of results, Figure 6 shows the spatial match-mismatch between the total actual and simulated lava flows. The intersection area measures $1.548 \mathrm{~km}_{2}$, which is more of the $66 \%$ of the actual lava flow field ( $\varepsilon$ score in Table 2 ). The areas wrongly covered (false positive) and wrongly not covered (false negative) by the simulated lava flows are $0.783 \mathrm{~km}^{2}$ and $0.493 \mathrm{~km}^{2}$, respectively.

\section{CONCLUSIONS}

We documented how the integration of satellite observations and numerical modeling represents an efficient strategy to forecast accurate and reliable eruptive scenarios. Satellite observations can be combined with field measurements to provide different kind of data, including the location and occurrence of eruptive events, effusion rate and volume estimates, front position and lava flow area. Numerical modelling can forecast lava flow inundation scenarios, promptly assessing lava flow hazards. The major strength of our strategy relies in the constant feedback between satellite observations and numerical modeling: satellite images are used by HOTSAT to continuously identify the active portions of lava flow fields and derive the TADR to run MAGFLOW simulations; conversely, model-based assessments of likely flow area are used to refine satellite conversion algorithms.

Here we have used the combination of the HOTSAT system with the MAGFLOW model during the six eruptive events occurred at Etna volcano between February and April 2017. We found that the total amount of lava flow erupted over the entire period is $\sim 11.3 \pm 2.8 \times 10^{6}$ $\mathrm{m}^{3}$, which divided per the total lava flow area (2.331 $\mathrm{km}^{2}$ ), provides an average thickness of $4.8 \pm 1.2 \mathrm{~m}$. The goodness of fit between actual and simulated lava flow areas, with all scores above 0.5 , has proven the reliability of our approach in assessing lava flow hazard. These encouraging results are also supported by a perfect fit with field data, available only for the eruptive event of 27 February (INGV UFMV Internal Report N.1/2017). Indeed the differences between the satellite- and field-derived areas $\left(0.321 \pm 0.075\right.$ vs $\left.0.306 \mathrm{~km}^{2}\right)$ and lava volumes $\left(1.19 \pm 0.297 \times 10^{6}\right.$ vs $\left.0.967 \times 10^{6} \mathrm{~m}^{3}\right)$ fall within the measurement errors.

An indirect finding of our results is also the importance of the availability of updated topographic data, especially on an active volcano, such as Mt Etna (Bilotta et al., 2019). Indeed, flow emplacements from eruptions occurred since the last update of the DEM may reduce the accuracy of subsequent scenarios, due to the formation of new topographic features that may influence the evolution of lava flows.

Finally, the local authorities charged with volcanic risk mitigation are interested in the evolution of an eruption: (i) what will happen; (ii) when will it probably happen; (iii) what are the likely consequences; (iv) whether it is getting worse; (v) whether it is over [Harris et al., 2016]. This means that the products delivered by a satellite-driven modeling approach for quantifying lava flow hazards during an ongoing eruption could be incorporated into the decision support system [INGV Weekly Report N¹5/2017].

Acknowledgements. Thanks are due to EUMETSAT for SEVIRI data (www.eumetsat.int). Pléiades data were available through the Space Volcano Observatory with Pléiades project (http://volcano.iterre.fr/svo_projects]. Landsat-8 and Sentinel-2 images are courtesy of the U.S. Geological Survey (earthexplorer.usgs.gov). INGV weekly reports are available at www.ct.ingv.it/it/rapporti/multidisciplinari.html. This work was developed within the framework of TecnoLab, the Laboratory for Technological Advance in Volcano Geophysics of the INGV in Catania (Italy) and was partially supported from the DPC-INGV 2012-2021 Agreement. This paper benefited from the comments and suggestions of two anonymous reviewers. 


\section{LIST OF ACRONYMS AND ABBREVIATIONS USED IN THE TEXT}

DEM - Digital Elevation Model

GMT - Greenwich Mean Time

INGV - Istituto Nazionale di Geofisica e Vulcanologia

MFS - Monte Frumento Supino

MOR - Mean Output Rate

MSG - Meteosat Second Generation

MSI - Multi Spectral Instrument

NSEC - New South East Crater

OLI - Operational Land Imager

SEC - South East Crater

SEVIRI - Spanning Enhanced Visible and Infrared Imager

TADR - Time-Averaged Discharge Rate

TIRS - Thermal Infrared Sensor

VdB - Valle del Bove

VdL - Valle del Leone

\section{REFERENCES}

Bilotta, G., A. Cappello, A. Hérault, A. Vicari, G. Russo, and C. Del Negro, (2012). Sensitivity analysis of the MAGFLOW Cellular Automaton model. Environ. Mod. Soft., 35, 122-131, doi:10.1016/j.envsoft.2012.02.015.

Bilotta, G., A. Cappello, A. Hérault, and C. Del Negro, (2019). Influence of topographic data uncertainties on the numerical simulation of lava flows. Environ. Mod. Soft., 112, 1-15, doi:10.1016/j.envsoft.2018.11.001.

Calvari, S., and H. Pinkerton, (1998). Formation of lava tubes and extensive flow field during the 1991-93 eruption of Mount Etna, J. Geophys. Res., 103, doi:10.1029/97JB03388.

Calvari, S., M. Neri and H. Pinkerton, (2003). Effusion rate estimations during the 1999 summit eruption on Mount Etna, and growth of two distinct lava flow fields. J. Volcanol. Geotherm. Res., 119, 107123, doi: 10.1016/S0377-0273(02)00308-6.

Cappello, A., A. Vicari, and C. Del Negro, C. (2011a). Assessment and Modeling of lava flow hazard on Etna volcano. Boll. Geof. Teor. Appl., Vol. 52, n.2, June 2011, 299-308.

Cappello, A., A. Vicari, and C. Del Negro, (2011b). Retrospective validation of a lava flow hazard map for Mount Etna volcano, Ann. Geophys., 54, 5, doi: 10.4401/ag-5345.
Cappello, A., G. Bilotta, M. Neri and C. Del Negro, C. (2013). Probabilistic modelling of future volcanic eruptions at Mount Etna, J. Geophys. Res.: Solid Earth, 118, doi:10.1002/jgrb.50190.

Cappello, A., N. Geshi, M. Neri and C. Del Negro, (2015a). Lava flow hazards - An impending threat for Miyakejima volcano, Japan. J. Volcanol. Geotherm. Res., 308, 1-9, doi:10.1016/j.jvolgeores.2015.10.005.

Cappello, A., V. Zanon, C. Del Negro, T.J.L., Ferreira and M.G.P.S. Queiroz, (2015b), Exploring lava-flow hazards at Pico Island, Azores Archipelago (Portugal). Terra Nova, 27 (2), 156-161, doi: 10.1111/ter.12143.

Cappello, A., G. Ganci, S. Calvari, N. M. Pérez, P.A. Hernández, S.V. Silva, J. Cabral, and C. Del Negro, (2016a). Lava Flow Hazard Modeling during the 2014-2015 Fogo eruption, Cape Verde. J. Geophys. Res.: Solid Earth, 121, 2290-2303, doi:10.1002/2015JB012666.

Cappello, A., A. Hérault, G. Bilotta, G. Ganci and C. Del Negro, (2016b). MAGFLOW: a physics-based model for the dynamics of lava-flow emplacement. In: Harris, A., De Groeve, T., F. Garel, and S.A. Carn, (eds) Detecting, Modelling and Responding to Effusive Eruptions. Geological Society, London, Special Publications, 426, 357-373, doi:10.1144/SP426.16.

Cappello, A., G. Ganci, G. Bilotta, C. Corradino, A. Hérault. and C. Del Negro, (2019). Changing Eruptive Styles at the South-East Crater of Mount Etna: Implications for Assessing Lava Flow Hazards. Front. Earth Sci., 7:213, doi: 10.3389/feart.2019.00213.

Cashman, K.V., S.A. Soule, B.H. Mackey, N.I. Deligne, N.D. Deardorff and H.R. Dietterich, (2013). How lava flows: New insights from applications of LiDAR technologies to lava flow studies: Geosphere, doi:10.1130/GES00706.1.

Del Negro, C., L. Fortuna, A. Herault, and A.Vicari, (2008). Simulations of the 2004 lava flow at Etna volcano by the MAGFLOW cellular automata model. Bull. Volcanol., 70, 805-812, doi:10.1007/s00445-007-0168-8.

Del Negro, C., A. Cappello and G. Ganci, G. (2016). Quantifying Lava Flow Hazards in Response to Effusive Eruption. The Geological Society of America Bulletin. doi:10.1130/B31364.1.

Ganci, G., A.J.L. Harris, C. Del Negro, Y. Guehenneux, A. 
Cappello, P. Labazuy, S. Calvari and M. Gouhier, (2012a). A year of lava fountaining at Etna: volumes from SEVIRI. Geophys. Res. Lett., 39, L06305. doi:10.1029/2012GL051026.

Ganci, G., A. Vicari, A. Cappello, and C. Del Negro, C. (2012b). An emergent strategy for volcano hazard assessment: From thermal satellite monitoring to lava flow modeling. Rem. Sens. Environ., vol. 119, 197-207. doi: 10.1016/j.rse.2011.12.021.

Ganci, G., G. Bilotta, A. Cappello, A. Hérault, and C. Del Negro, (2016). HOTSAT: a multiplatform system for the satellite thermal monitoring of volcanic activity. In: Harris, A., T. De Groeve, F. Garel \& S. A. Carn, (eds) Detecting, Modelling and Responding to Effusive Eruptions. Geological Society, London, Special Publications, 426, doi: 10.1144/SP426.21.

Ganci, G., A. Cappello, G. Bilotta, A. Hérault, V. Zago and C. Del Negro, C. (2018). Mapping volcanic deposits of the 2011-2015 Etna eruptive events using satellite remote sensing, Frontiers in Earth Science 6:83. doi:10.3389/feart.2018.00083.

Garel F., E. Kaminski, S. Tait and A. Limare, (2012). An experimental study of the surface thermal signature of hot subaerial isoviscous gravity currents: implications for thermal monitoring of lava flows and domes. J. Geophys. Res., 117, B02205.

Garel F., E. Kaminski, S. Tait and A. Limare, (2015). A fluid dynamics perspective on the interpretation of the surface thermal signal of lava flows. From: A. J. L Harris, T. De Groeve, T., F. Garel \&t S. A. Carn (eds) 2016. Detecting, Modelling and Responding to Effusive Eruptions. Geological Society, London, Special Publications, 426, doi:10.1144/SP426.6.

Harris, A.J.L., S. Blake, D. Rothery and N. Stevens, (1997). A chronology of the 1991 to 1993 Mount Etna eruption using advanced very high resolution radiometer data: implications for real-time thermal volcano monitoring. J. Geophys. Res., 102, 7985-8003.

Harris, A.J.L. and S. Rowland, (2001), FLOWGO: A kinematic thermorheological model for lava flowing in a channel, Bull. Volcanol. 63:1, 20-44, doi:10.1007/s004450000120.

Harris, A.J.L., S. Carn, J. Dehn, C. Del Negro, M.T. Gu ? mundsson, B. Cordonnier, T. Barnie, E. Chahi, S. Calvari, T. Catry, T. De Groeve, D. Coppola, A. Davies, M. Favalli, F. Ferrucci, E. Fujita, G. Ganci., F. Garel, P. Huet, J. Kauahikaua, K.Kelfoun, V. Lombardo, G. Macedonio, J. Pacheco, M. Patrick, N. Pergola, M. Ramsey, R. Rongo, F. Sahy, K. Smith, S. Tarquini, T.
Thordarson, N. Villeneuve, P. Webley, R. Wright and K. Zakšek, (2016). Conclusion: recommendations and findings of the RED SEED working group. From: Harris, A. J. L., De T. Groeve, F. Garel. \&t S. A. Carn, (eds) 2016. Detecting, Modelling and Responding to Effusive Eruptions. Geological Society, London, Special Publications, 426, 567-648, http://doi.org/10.1144/SP426.11.

Hérault, A., A. Vicari, A. Ciraudo and C. Del Negro, C. (2009). Forecasting lava flow hazards during the 2006 Etna eruption: Using the MAGFLOW cellular automata model. Computer \& Geosciences, 35, 10501060, doi: 10.1016/j.cageo.2007.10.008.

Kereszturi, G., A. Cappello, G. Ganci, J. Procter, K. Németh, C. Del Negro, and S.J. Cronin, (2014). Numerical simulation of basaltic lava flows in the Auckland Volcanic Field, New Zealand - Implication for volcanic hazard assessment. Bull. Volcanol. 76:879, doi:10.1007/s00445-014-0879-6.

Latutrie, B., I. Andredakis, T. De Groeve, A. Harris, E. Langlois, B. van Wyk de Vries, E. Saubin, G. Bilotta, A. Cappello, G.M. Crisci, D. D’Ambrosio, C. Del Negro, M. Favalli, E. Fujita, G. Iovine, K. Kelfoun, R. Rongo, W.W. Spataro, S. Tarquini, D. Coppola, G. Ganci, F. Marchese, N. Pergola and V. Tramutoli, (2016). Testing a geographical Information system for damage and evacuation assessment during an effusive volcanic crisis. In: Harris, A., T. De Groeve., F. Garel, F. \& S. A. Carn (eds) Detecting, Modelling and Responding to Effusive Eruptions. Geological Society, London, Special Publications, 426, doi:10.1144/SP426.19.

Lautze, N.C., A.J.L Harris, J.E. Bailey, M. Ripepe, S. Calvari, J. Dehn., S.K Rowland and K. Evans-Jones, (2004). Pulsed lava effusion at Mount Etna during 2001. J. Volcanol. Geotherm. Res., 137, 231-246, doi:10.1016/j.jvolgeores.2004.05.018.

Vicari, A., G. Ganci, B. Behncke, A. Cappello, A., M. Neri, and C. Del Negro, (2011). Near-real-time forecasting of lava flow hazards during the 12-13 January 2011 Etna eruption, Geophys. Res. Lett., 38, L13317. doi: 10.1029/2011GL047545.

Walker, G.P.L. (1973). Mount Etna and the 1971 eruption - Lengths of lava flows. Phil. Trans. R. Soc. Lond., A 274, 107-118, doi:10.1098/rsta.1973.0030.

Wright, R., A. Blake, S., A. Harris and D. Rothery, (2001) A simple explanation for the space-based calculation of lava eruption rates. Earth Planet Sci. Lett. 192, 223-233. 
LAVA FLOW HAZARD MONITORING: ETNA 2017

"CORRESPONDING AUTHOR: Annalisa CAPPELLO,

Istituto Nazionale di Geofisica e Vulcanologia,

Osservatorio Etneo, Sezione di Catania

Catania, Italy

email: annalisa.cappello@ingv.it

(c) 2019 the Istituto Nazionale di Geofisica e Vulcanologia.

All rights reserved 